Objectives: Evaluate the feasibility of a simple clinical joint damage score and describe the increment over time in RA patients with varying disease duration. Methods: Cross-sectional study in all patients with a clinical diagnosis of RA visiting the outpatient clinic in 2015 and 2016. Rheumatologists and nurses from the outpatient department of a large regional hospital received a single training to perform the RAAD score. Scores of 0 (no damage), 1 (mild) or 2 (severe: ankylosis, luxation or joint surgery) were assigned to 35 joints (maximum score: 70) with a disease activity score, and stored in the electronic patient record system. Baseline data including ACR 2010 criteria were also registered.

Results: In 1007 (67.3\%) of 1496 RA patients seen over 2 years RAAD-scores were performed. $652(64.7 \%)$ were female, average age (SD, range) was 62.6 (13.1, 19-95), disease duration $9.9(9.6,0-65)$ years. Rheumatoid factor and ACPA were positive in $70.6 \%$ and $70.3 \%$ respectively.

RAAD scores related to disease duration illustrate that at disease onset $86 \%$, and after 20 years $37 \%$ of the patients has no joint damage (Table). Distribution over joints shows the classical predominance of damage in MCP, PIP and MTP joints (Image). Structural damage in shoulders or elbows was present in $8.3 \%$ and $12.5 \%$, in knees and hips in 10,3\% each. Despite current treatment strategies, irreversible joint damage of more than 5 joints is present in $6.3 \%$ within 10 years.

Table 1. Accumulation of irreversible joint damage score with disease duration, number (\%)

\begin{tabular}{lccccc}
\hline RAAD-score & $\begin{array}{c}\text { 1st year } \\
(\mathrm{N}=69)\end{array}$ & $\begin{array}{c}2-4 \text { yrs } \\
(\mathrm{N}=228\end{array}$ & $\begin{array}{c}5-9 \text { yrs } \\
(\mathrm{N}=253)\end{array}$ & $\begin{array}{c}10-19 \mathrm{yrs}) \\
(\mathrm{N}=239)\end{array}$ & $\begin{array}{c}\geq 20 \mathrm{yrs} \\
(\mathrm{N}=218)\end{array}$ \\
\hline 0 (no joint damage) & $59(86)$ & $158(69.3)$ & $145(57.3)$ & $81(33.9)$ & $80(36.7)$ \\
$1-5$ & $8(12)$ & $65(28.5)$ & $92(36.4)$ & $103(43.1)$ & $42(19.3)$ \\
$6-10$ & $2(3)$ & $4(1.8)$ & $11(4.3)$ & $34(14.2)$ & $28(12.8)$ \\
$11-20$ & & & $4(1.6)$ & $13(5.4)$ & $36(16.5)$ \\
$>20$ & & $1(0.4)$ & $1(0.4)$ & $8(3.3)$ & $32(14.7)$ \\
Average (range) & $0,4(0-6)$ & $0,9(0-23)$ & $1,6(0-37)$ & $2,2(0-18)$ & $9,0(0-59)$ \\
\hline
\end{tabular}

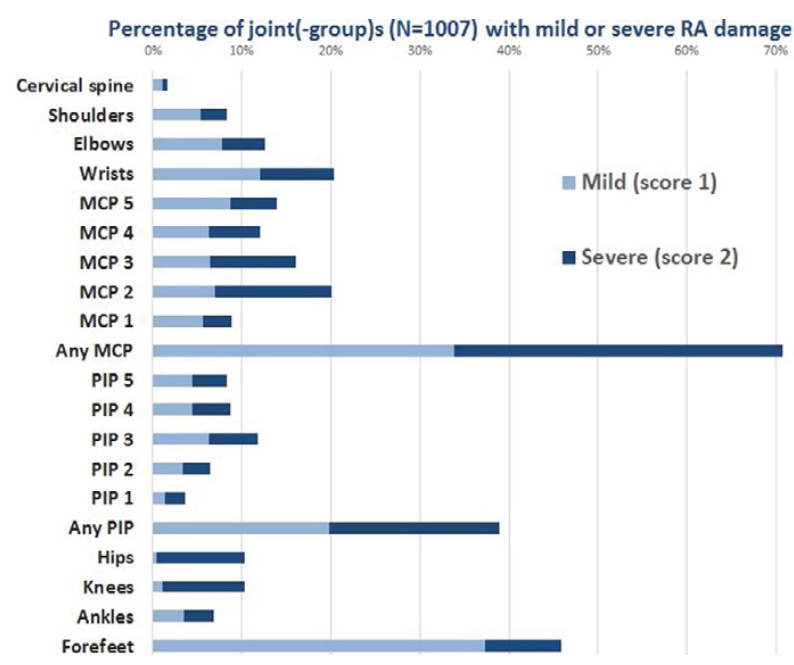

Conclusions: Clinical assessment of joint damage is a feasible parameter of long term outcome in RA. Reflecting overall joint damage, the RAAD-score provides a broader view than radiographic scoring of hands and feet and is easy to apply in routine care. Given the slow increment a single assessment per 5 years may suffice to compare structural joint damage across cohorts of patients.

References:

[1] Zijlstra T, Bernelot Moens H, Bukhari M. The rheumatoid arthritis articular damage score: first steps in developing a clinical index of long term damage in RA. Ann Rheum Dis. 2002;61:20-3.

[2] Hammer $\mathrm{H}$, Odegard $\mathrm{S}$, Fagerhol $\mathrm{M}$, et al. Calprotectin is strongly and independently correlated with joint inflammation and damage in rheumatoid arthritis. Ann Rheum Dis 2007;66:1093-7.

Disclosure of Interest: None declared

DOI: 10.1136/annrheumdis-2017-eular.4437

\section{THU0107 ASSOCIATION OF GLOBAL DNA METHYLATION WITH MTX RESPONSE AND ADVERSE EVENTS IN EARLY RHEUMATOID ARTHRITIS}

H. Gosselt ${ }^{1}$, M.D. Rotte ${ }^{1}$, M. Chisholm ${ }^{1}$, M. Hazes ${ }^{2}$, R.D. Jonge ${ }^{3}$, S. Heil ${ }^{1}$ ${ }^{1}$ Clinical Chemistry; ${ }^{2}$ Rheumatology, Erasmus Medical Center, Rotterdam; ${ }^{3}$ Clinical Chemistry, VUMC, Amsterdam, Netherlands

Background: Methotrexate (MTX) is a first-line therapy in early Rheumatoid Arthritis (RA). However, $\sim 30 \%$ of treated patients do not respond to the medicine or need to abrogate treatment because of severe adverse events. Since MTX interferes with the folate cycle and thereby influences the methylation cycle, we hypothesize that methylation status at start therapy is associated with response and adverse events after three months of MTX treatment enabling personalized medicine.
Objectives: Examine global methylation status of early Rheumatoid Arhtritis patients before and after 3 months of MTX use between responders and non-responders and patients that do or do not experience adverse events.

Methods: To assess global methylation status, DNA was isolated at baseline from whole blood of 120 patients from the Treatment in the Rotterdam Early Arthritis Cohort (tREACH), a multicenter, stratified single-blind clinical trial of patients with early RA. Methylation status of $7 \mathrm{CpG}$ sites within Long-interspersed nuclear elements (LINE-1) were analyzed and quantified by Matrix Assisted Laser Desorption lonization time of flight Mass Spectrometry (MALDI-TOF MS). Results were compared between MTX responders and non-responders based on a low disease activity (DAS28 <3.2) at three months of treatment and patients experiencing $\leq 2$ or $\geq 3$ adverse events. Gastrointestinal adverse events were assessed separately.

Results: No statistical differences in the mean of 7 LINE-1 CpGs were observed between responders and non-responders, nor in patients experiencing $\leq 2$ or $>3$ adverse events. However, methylation status of specific CpG sites within LINE-1 did show significant changes. Baseline CpG_2 methylation levels were positively correlated with the DAS28 score at $\mathrm{t} 3(\mathrm{p}=0.018)$ and baseline methylation levels in CpG_5 and CpG_8.9 were significantly higher in patients experiencing $\geq 3$ adverse events $(p=0.018$ and $p=0.034$, respectively). Besides, CpG_5 methylation levels were particularly increased in patients experiencing gastrointestinal adverse events $(p=0.038)$

Conclusions: Global methylation status is associated with non-response and adverse events to MTX in early RA patients and can therefore be implemented in future prediction models.

Disclosure of Interest: None declared

DOI: 10.1136/annrheumdis-2017-eular.4686

\section{THU0108 SUBCLINICAL CENTRAL NERVOUS SYSTEM DAMAGE IN PATIENTS WITH RHEUMATOID ARTHRITIS: DISEASE ACTIVITY AND CYTOKINES}

I. Tekeoğlu, S. Sağ, A. Kamanlı, M.S. Sağ, K. Nas. Department of Physical Medicine and Rehabilitation, Rheumatology, Faculty of Medicine, Sakarya University, Sakarya, Turkey, sakarya, Turkey

Background: We aimed in this study to investigate blood-brain barrier (BBB) dysfunction in RA patients who had no neurological symptoms, and were receiving synthetic DMARD treatment.

Objectives: We investigated correlations between cranial MRI images and brain specific proteins (S100 Beta, GFAP), cytokines (IL-1 beta, IL-17) in plasma which had important roles in disease activity.

Methods: In our study, 57 patients (46 females and 11 males) were included included in RA group, and 34 patients (24 females and 10 males) in the control group. All of RA patients were receiving synthetic DMARD treatment. Demographic characteristics of all patients were recorded. Disease activity was evaluated by using DAS-28. Mini-mental test (MMT) was used for evaluation of cognitive functions, and Fazekas scale was used to evaluate cranial MR lesions. S100 beta, GFAP, claudin, IL-17, and IL-1 beta levels were measured in peripheral blood of both groups.

Results: Demographic characteristics were similar between the groups, and there was no statistically significant difference in gender, age, and body mass index (BMI) between patient and control groups $(p>0.05)$. S100 beta, and GFAP levels were significantly higher in RA group $(p<0.05)$. No difference was determined in hyperintense lesions diagnosed in cranial MR between patient and control groups $(p>0.05)$. There were positive correlations between IL-17 S100 beta and GFAP, and IL-1 beta and S100 beta.

Conclusions: In our study, we have shown that blood-brain barrier may be damaged subclinically in RA patients, brain specific proteins related to BBB dysfunction may be increased in the peripheral blood, and BBB dysfunction may be related to cytokines which play an important role in disease pathogenesis. In conclusion, cytokines which circulate in the peripheral blood in RA may cause subclinical BBB damage. Further large scale studies with long-term follow-up are required which will support this hypothesis.

Disclosure of Interest: None declared

DOI: 10.1136/annrheumdis-2017-eular.2313

\section{THU0109 UPDATED ESTIMATION OF THE EQ5D QUALITY OF LIFE QUESTIONNAIRE UTILITY VALUES THROUGH HAQ-DI MAPPING FOR SPAIN}

I. Gorostiza ${ }^{1}$, L. Ansola ${ }^{2}$, E. Galindez ${ }^{3} \cdot{ }^{1}$ Research Unit; ${ }^{2}$ Research Unit; ${ }^{3}$ Rheumatology, H. Universitario Basurto, Vizcaya, Spain

Background: Rheumatoid arthritis (RA) deeply affects the quality of life (QoL) of patients. The preferred approach to evaluate treatment efficiency is to value health as patient preferences known as utilities, and subsequently, calculate Quality-Adjusted Life Years gained. A new 5-level of severity EQ5D has recently released and a new tariff proposed for Spain (Ramos-Goñi,2016). Although QoL questionnaires are not of routine use in clinical practice, it is possible to estimate it using the Health Assessment Questionnaire Disability Index (HAQ-DI)

Objectives: To develop a function that allows the estimation of EQ5D-5L utility values from HAQ-DI updated to the newest proposed tariff for Spain 